\title{
SINCLINAL OURO FINO REVISITADO, QUADRILÁTERO FERRÍFERO, MINAS GERAIS: UMA HIPÓTESE SOBRE A SUA ORIGEM E EVOLUÇÃO
}

\author{
ANTÔNIO SÉRGIO PONZO FRANCO ${ }^{1} \&$ ISSAMU ENDO $^{2}$
}

\begin{abstract}
OURO FINO SYNCLINE REVIEWED, QUADRILÁTERO FERRÍFERO, MINAS GERAIS: A HYPOTHESIS FOR ITS ORIGIN AND EVOLUTION The Ouro Fino Syncline is a regional structure with a controversial origin. Two structural models represent the synthesis to its tectonic evolution. On the one hand, according to Ladeira \& Viveiros (1984), the Ouro Fino syncline is the result of the first folding event which affected the Minas Supergroup. These folds present E-W trending axes and associated penetrative cleavage. The tectonic transport vector is northward. On the other hand, Fonseca (1990), interprets Ouro Fino syncline's origin as a result of compressive forces directed to westward. The axis has $\mathrm{N}$-S trending and westward vergence according to Dorr (1969). This second point of view is the most accepted model. However the present investigation of the Ouro Fino syncline allowed to characterize four families of structures and to present a third hypothesis for its origin and evolution. The first family is characterized by tight and reclined folds with moderate ESE plunging fold axis. The other structures of this phase are the axial plane schistosity and the mineral lineation parallel to intersection lineation. The mineral lineation is characterized as a "b" type fabric. The iron mineralization is closely related to the strain parameters of the first deformation phase. The fold closure occurs in the southern region of the Ouro Fino Syncline defined by structural relationships between bedding and schistosity and by subsidiary " $\mathrm{S}$ " and " $\mathrm{Z}$ " folds in the west and east limbs respectively. These relations allow to redefine the Ouro Fino structure as a reclined antiformic synclinorial fold with southward vergence and axis plunging to ESE. In this case the paleoproterozoic Minas Supergroup units occupy the fold nucleus being enveloped by the archean Rio das Velhas Supergroup metapelitic sequence. The second deformation phase is characterized by tight to open folds with sub-horizontal N-S trending axes genetically related to the Córrego das Flechas fault. The notable fold for this phase is the footwall Córrego das Flechas synform with westward vergence. The other families are represented by crenulations and $\mathrm{E}-\mathrm{W}$ and $\mathrm{N}-\mathrm{S}$ axial trending gentle folds.
\end{abstract}

Keywords: Structural Geology, Tectonic Evolution, Ouro Fino Syncline, Quadrilátero Ferrífero, Capanema mine.

Resumo OSinclinal Ouro Fino é uma estrutura de escala sub-regional de origem controvertida. Dois modelos estruturais constituem a visão síntese da evolução tectônica dessa estrutura. Para Ladeira \& Viveiros (1984) o Sinclinal Ouro Fino resulta do primeiro evento de dobramento que afetou o Supergrupo Minas, tendo gerado as primeiras dobras com eixos E-W e clivagem penetrativa associada. A vergência desta fase de dobramento é para norte. Já Fonseca (1990) interpreta a origem do Sinclinal Ouro Fino como resultado de esforços compressivos dirigidos de E para W. O eixo teria orientação submeridiana e vergência para oeste tal como foi apresentado por Dorr (1969). Este último é o modelo amplamente aceito. Entretanto, a presente investigação por meio da análise estrutural conduzida no Sinclinal Ouro Fino permitiu a caracterização de quatro famílias distintas de estruturas e a proposição de uma outra hipótese para a origem e evolução dessa estrutura. A primeira família caracteriza-se por dobramentos apertados e reclinados com charneiras apresentando caimentos moderados para ESE tendo gerado uma xistosidade plano-axial e lineação de interseção paralela à lineação mineral. Esta lineação mineral caracteriza-se como do tipo "b". A mineralização ferrífera está fortemente condicionada pelos parâmetros deformacionais desta fase. O fechamento da dobra de primeira ordem se dá no setor meridional sendo corroborado pelas relações entre o acamamento e a xistosidade e pelas dobras subsidiárias em padrão "S" e em "Z", respectivamente, nos flancos oeste e leste. Essas relações permitem redefinir a geometria da estrutura de Ouro Fino como uma dobra sinclinorial, de eixo WNW-ESE subhorizontal, antifórmica, reclinada e vergência para sul. Nestas condições tem-se que as unidades do Supergrupo Minas (Paleoproterozóico) ocupam o núcleo da dobra sendo envolvidas pela sequêencia metapelítica do Supergrupo Rio das Velhas (Arqueano). A segunda família de estruturas é caracterizada por dobras abertas a fechadas com eixos subhorizontais orientados em posição submeridiana associada à lapa da falha Córrego das Flechas. A dobra notável desta fase é o sinforme Córrego das Flechas. Elas apresentam clivagens planoaxiais. A vergência e o transporte tectônico são de leste para oeste. As demais famílias estão representadas por dobramentos suaves e crenulações com direções axiais E-W e N-S.

Palavras-chave: Geologia Estrutural, EvoluçãoTectônica, Sinclinal Ouro Fino, Quadrilátero Ferrífero, Mina de Capanema.

INTRODUÇÃO OSinclinal Ouro Finoé uma das megaestruturas do arcabouço estrutural do Quadrilátero Ferrífero (QFe). Está situado na parte centro-sudeste do estado de Minas Gerais, a $25 \mathrm{~km}$ da cidade de Itabirito (Fig. 1). Geologicamente, localiza-se na porção centro-leste do Quadrilátero Ferrífero sendo sua área de aproximadamente $23 \mathrm{Km}^{2}$. A presente investigação teve como ponto de partida o mapeamento lito-estrutural da formação ferrífera do Grupo Itabira em escalas de 1:1.000 e 1:2.000 e estendendo-se às rochas encaixantes do Grupo Caraça com o objetivo de levantar parâmetros sobre a origem e evolução desta estrutura e novos condicionantes para o modelo prospectivo de minério de ferro. Para se atingir o objetivo proposto, utilizou-se a metodologia clássica de análise estrutural de seqüências sedimentares polideformadas de baixo grau metamórfico, fundamentalmente aquelas relacionadas aos sistemas dobrados.

Com base nas relações estruturais, propõe-se um modelo

1 - Companhia Vale do Rio Doce, Mina de Alegria, Fazenda Alegria, Mariana-MG, Caixa Postal 02, CEP 35420-000, antonio.sergio.franco@cvrd.com.br 2 - Departamento de Geologia da Escola de Minas, Universidade Federal de Ouro Preto (DEGEO/EM/UFOP), Campus Universitário, Ouro Preto-MG, CEP 35400-000. issamu@degeo.ufop.br 


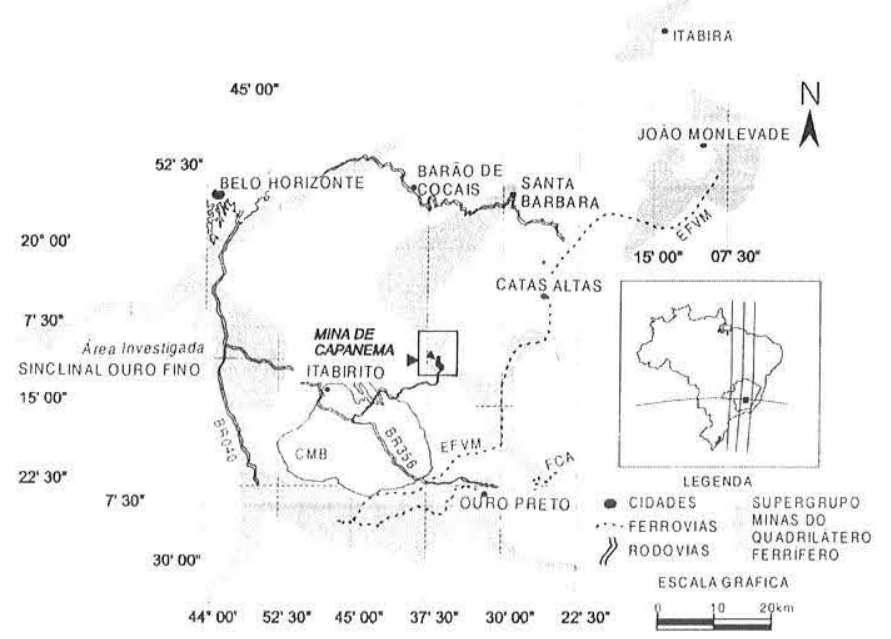

Figura I - Mapa de localização e acesso ao Sinclinal Ouro Fino.

alternativo de evolução estrutural para o Sinclinal Ouro Fino. Na presente interpretação o Sinclinal Ouro Fino configura-se como uma dobra reclinada com eixo na direção aproximada EW, formada no primeiro evento de dobramento que afetou as unidades do Supergrupo Minas. O sinclinal, com a geometria de uma dobra normal invertida com eixo subhorizontal NS, como descrito na literatura, refere-se à segunda fase de dobramento.

ESTUDOS PRÉVIOS Os primeiros estudos sistemáticos realizados na Serra de Ouro Fino iniciaram-se com Harder \& Chamberlin (1915), Morais Rego (1933) e O'Rourke (1957). Para O'Rourke (1957), que além de definir a estratigrafia para a região, considerou os sinclinais Ouro Fino e Gandarela originalmente separados por um antiforme e, posteriormente, truncados por falhas. Como extensão dos sinclinais Ouro Fino e Gandarela, Maxwell (1960) inclui o Sinclinal Conta História, todos com eixos supostamente de direção submeridiana e caimento subhorizontal. Para Dorr (1969) a porção norte do sinclinal teria sido reorientada, sendo sua posição original NW-SE com eixo subhorizontal, posicionada paralelamente ao Sinclinal Vargem do Lima. Dorr (1969) estimou um deslocamento mínimo de $5 \mathrm{~km}$ ao longo da Falha do Fundão para a completa rotação tectônica do segmento setentrional do Sinclinal Ouro Fino.

Ladeira \& Viveiros (1984) identificaram seis eventos deformativos envolvendo as unidades dos supergrupos Rio das Velhas e Minas. O primeiro afetou apenas as unidades do Supergrupo Rio das Velhas. O segundo evento, o mais importante para o Supergrupo Minas, foi responsável pelo desenvolvimento de xistosidade penetrativa associada a dobramentos com vergência para norte seguida de transposição generalizada. Aquele autor suspeitou que a direção das charneiras dessa fase é EW, com a vergência tectônica para norte. Segundo o mesmo autor, esses dados são baseados em algumas poucas estruturas relicticas dessa fase, não podendo ser definidas com segurança. Os eventos $\mathrm{D}_{3} \mathrm{e}$ $\mathrm{D}_{4}$ seriam caracterizados por dobramentos coaxiais, com vergência para norte. O evento $\mathrm{D}_{5}$ tem direção geral NS, sendo caracterizado por dobras abertas e pelo padrão em kink. O último evento $\mathrm{D}_{6}$ corresponderia ao desenvolvimento de fraturas. Fonseca (1990) propõe um quadro evolutivo para o Sinclinal Ouro Fino, constituído por três fases de deformação. A primeira fase é representada por dobramento não-coaxial em domínio dúctil resultante da compressão tectônica com esforços dirigidos de $\mathrm{E}$ para W. Nessa fase teriam se formado o Sinclinal Ouro Fino e o Sistema de Falhas do Fundão. A segunda fase de deformação foi responsável pela geração de estruturas orientadas na direção EW e pelo redobramento do sinclinal que resultou na sua forma atual. A terceira fase pode ser caracterizada por uma compressão tectônica com vetores orientados na direção EW, gerando estruturas NS do tipo kink bands e dobras flexurais normais. Fonseca (1990) observou que a lineação de interseção entre o acamamento e a xistosidade principal se posicionava subparalelamente à lineação mineral. Fonseca \& Alkmim (1992) sugeriram que um movimento de arrasto ao longo do Sistema Fundão teria sido a causa do desmembramento dos sinclinais Ouro Fino e Conta-História.

CONTEXTO GEOLÓGICO Os estratos que definem a estrutura do Sinclinal Ouro Fino constituem as unidades basal e intermediária do Supergrupo Minas, que se assentam em discordância tectônica sobre as seqüências arqueanas do greenstone belt Rio das Velhas (Fig. 2). Estão representadas, nesta ordem, pelas rochas dos grupos Caraça e Itabira. O Grupo Piracicaba não se encontra preservado nesse sinclinal.

O Grupo Caraça é constituído por quartzitos da Formação Moeda e filitos da Formação Batatal. O Grupo Itabira está representado pelos itabiritos da Formação Cauê e forma o núcleo do sinclinal. Os quartzitos do Grupo Caraça definem o contorno do Sinclinal Ouro Fino, com exceção do setor setentrional onde, no flanco leste, as rochas do Supergrupo Rio das Velhas estão sobrepostas

\begin{tabular}{|c|c|c|c|c|}
\hline Idade & Supergrupo & Girupo & Formaçầo & litologia \\
\hline & & & & Sedimentos cenozóicos \\
\hline \multirow{10}{*}{ 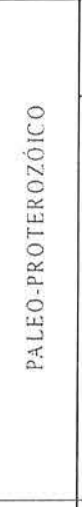 } & & 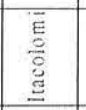 & Indiviso & 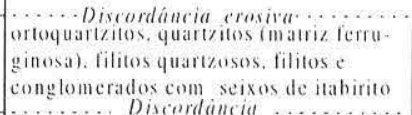 \\
\hline & \multirow{9}{*}{ 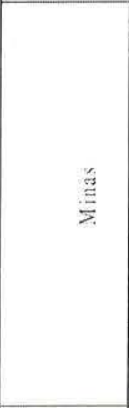 } & Sabari & Indiviso & $\begin{array}{c}\text { chirita-xistos. grauvacas, metatufos. } \\
\text { conglomerados e quartzitos }\end{array}$ \\
\hline & & \multirow{4}{*}{ 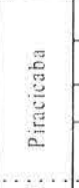 } & Barreiro & filitos e filitos grafitosos \\
\hline & & & Tabooes & ortoquartzitos \\
\hline & & & Fecho do Funil & filitos. libito dolomitico ed dolomito \\
\hline & & & & $\begin{array}{l}\text { quartzito lerruginoso, quartzitos. } \\
\text { filitos ferruginosos e dolomitos } \\
\text {..... Discordancio erosita } \ldots . . .\end{array}$ \\
\hline & & \multirow{2}{*}{ 冚 } & Gandarela & dolom itos. filito dolom itico e calcário \\
\hline & & & Cauê & itabirito, itabirito dolomitico e hematita \\
\hline & & \multirow{2}{*}{ 恚 } & Batatal & lilito e filitos grafitosos \\
\hline & & & Moeda & \multirow{2}{*}{$\begin{array}{l}\text { sericita-quartzito, conglomerados, filitos } \\
\text { …Discordância tectônica .......... } \\
\text { quarzitos, conglomerados. } \\
\text { scricita-quartzo-xistos c filitos }\end{array}$} \\
\hline \multirow{4}{*}{ 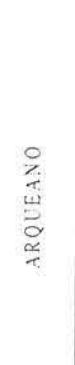 } & \multirow{4}{*}{ 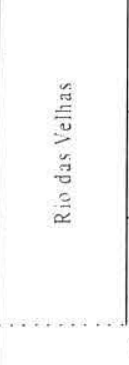 } & 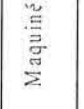 & Indiviso & \\
\hline & & 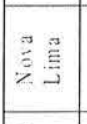 & Indivisu & 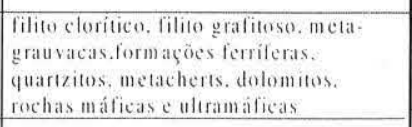 \\
\hline & & 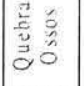 & Indiviso & $\begin{array}{l}\text { komatiitos, formaçoes ferriferase } \\
\text { metacherts }\end{array}$ \\
\hline & & \multicolumn{3}{|c|}{ iplexos granito-gnaissicos migmaltiticos. indivisos } \\
\hline
\end{tabular}

Figura 2 - Coluna litoestratigráfica simplificada do Quadrilátero Ferrífero (mod. Dorr 1969, Schorscher 1978, Ladeira 1980, Rodrigues et al. 1993). Em cinza está a coluna litoestratigráfica local simplificada. 
diretamente à Formação Cauê por contato de falha (Fig. 3) (Fonseca, 1990). A formação ferrífera da área pode ser dividida em dois grupos, o primeiro formado por itabiritos (s.s.), na base, contendo quartzo, hematita ( \pm magnetita, martita, especularita) e goethita, e o segundo constituído por itabiritos goethíticos-limoníticos, sobreposto ao primeiro. Quanto ao grau metamórfico, a paragênese contendo biotita e clorita verificada através do exame petrográfico dos itabiritos, sugere que as condições metamórficas atingiram, no máximo, o grau médio. A clorita, vista em seções delgadas, evidencia um retrometamorfismo; não sendo, portanto, indicadora do grau metamórfico. Já a biotita pode representar a faixa de temperatura mais provável alcançada pelo metamorfismo em questão.

O sinclinal é delimitado por um sistema de falhas reversas associadas ao sistema de falhas do Fundão. Observa-se que o traço da falha mestra desse sistema inflete da direção NW-SE a sul, para NE-SW a norte, sugerindo que a porção mediana do sinclinal tenha sido palco de uma tectônica de rampa frontal durante o evento compressivo $\mathrm{D}_{2}, \mathrm{EW}$.

ANÁLISE ESTRUTURAL A formação ferrífera foi dividida em cinco domínios (Fig. 4). Os critérios utilizados para a subdivisão basearam-se em características estruturais, como a magnitude de deformação, mudança no padrão de orientação de charneiras de dobra e de xistosidade SI.

Dados Estruturais ACAMAMENTO $S_{0}$ Nos quartzitos da Formação Moeda é comum observar estruturas primárias preservadas. O acamamento é definido pela diferença granulométrica, sendo marcante a presença de camadas de metaconglomerados intercaladas aos quartzitos. Estratificações cruzadas de pequeno e médio porte são também observadas. Nos filitos, o acamamento é caracterizado por variações granulométricas e composicionais, sendo possível encontrar finos estratos quartzosos intercalados aos níveis metapelíticos. Na Formação Ferrífera Cauê, o acamamento é definido pela variação na composição dos itabiritos, passando gradacionalmente, para o topo, para itabirito goethítico-limonítico.

O contorno do Sinclinal Ouro Fino é definido pelo acamamento, cuja trajetória é controlada principalmente pelos dobramentos decorrentes das duas primeiras fases $\mathrm{D}_{1} \mathrm{e}_{2}$, e descreve a trajetória de uma dobra recumbente com eixo na direçã̃o EW. O redobramento decorrente da fase $\mathrm{D}_{2}$ proporcionou a geração de dobra com eixo aproximado NS, causando ampla reorientação nas atitudes do acamamento primário (Fig. 5a). Em alguns locais, o acamamento $\mathrm{S}_{0}$ está parcial ou totalmente transposto pela fase $\mathrm{D}_{2}$. Próximo à Falha do Fundão, a transposição é bem acentuada, e a xistosidade $\mathrm{S}_{2}$ passa a ser a estrutura principal.

Estruturas da Fase $\mathbf{D}_{1}$ XISTOSIDADE, DOBRAS ELINEAÇÕES A xistosidade $\mathrm{S}_{1}$ constitui a estrutura planar penetrativa relacionada ao primeiro evento de dobramento reconhecido nas rochas do Supergrupo Minas. Ela ocorre tanto nos itabiritos quanto nas encaixantes, sendo que os afloramentos que melhor ilustram as relações de corte entre o acamamento e a xistosidade $S_{\text {, }}$ estão nas encaixantes. A cartografia das dobras subsidiárias $\mathrm{F}_{1}$ em torno do
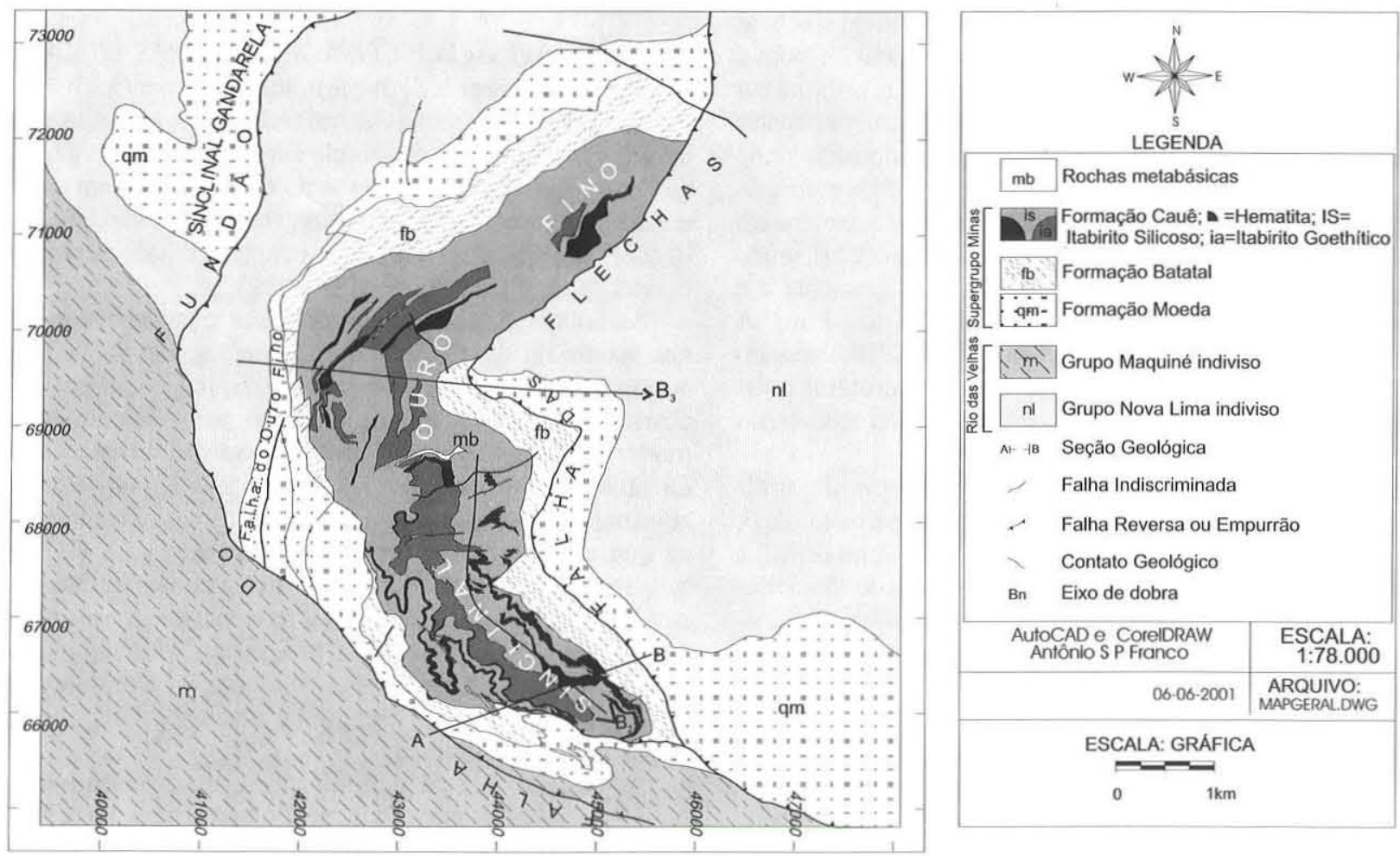

Figura 3 - Mapa geológico simplificado do Sinclinal Ouro Fino (modificado O'Rourke 1957, Maxwell 1960, Fonseca 1990, Sad \& Castro 2000, Vaz de Melo \& Seabra Jr: 2000, Franco 2002). As camadas de minério rico ou hematitas mostram o padrão de dobramento. 


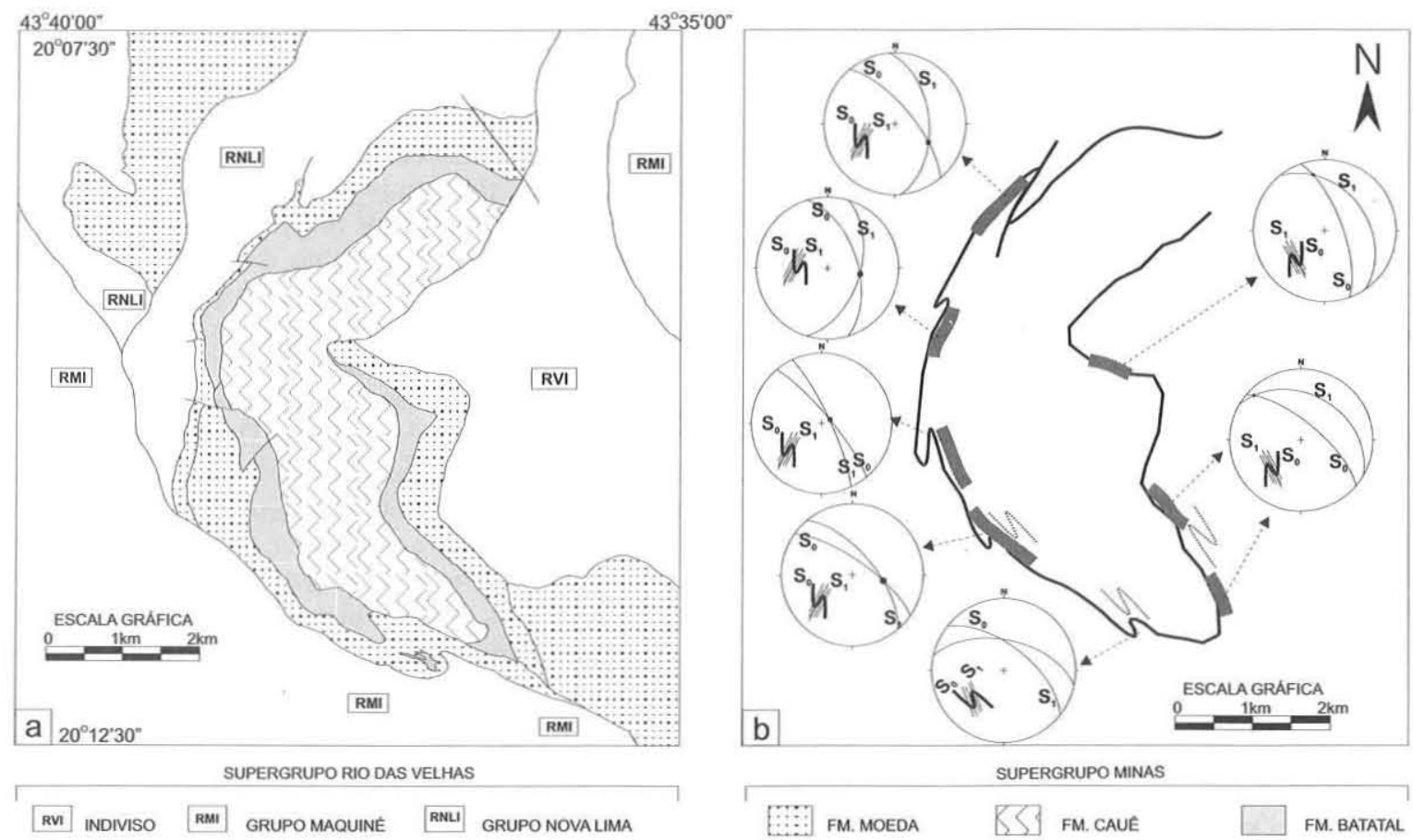

Figura 4 - Mapa geológico simplificado do Sinclinal Ouro Fino. (a) Domínios estruturais. (b) Setores notáveis ao redor do Sinclinal Ouro Fino onde se observam as relações entre o acamamento e a xistosidade $S_{\text {, }}$

sinclinal e o levantamento das relações de corte entre o acamamento e a xistosidade $S_{1}$, mostrou que o segmento ocidental do sinclinal representa o locus de ocorrência de dobras em padrão "S"com a xistosidade $S_{1}$ ocupando a posição plano-axial e oblíqua ao acamamento com atitude média de $105 / 50$ (Fig. 5b). A contraparte da estrutura, o segmento oriental, corresponde ao domínio onde predominam dobras em padrão do tipo " $Z$ " com atitude média de 035/40 (Fig. 4b, 5b). A interseção entre os planos do acamamento $\mathrm{S}_{0}$ e a xistosidade $\mathrm{S}_{1}$ apresenta caimento moderado para ESE, sendo paralela aos eixos de dobra B. Essa trama é proeminente e é observada em todos os litotipos do Sinclinal Ouro Fino. A concentração máxima possui valor em torno de 110/40, variando de 090/50 a 140/48 (Fig. 5c), exceto no domínio estrutural 1 que possui direção aproximadamente NS com caimentos moderados ora para norte ora para sul.

A família de dobras $F_{\text {, }}$ é composta por dobras flexurais assimétricas, de charneiras retilíneas e curvas. As charneiras de $F_{\text {, }}$ apresentam caimentos para ESE com valores em torno de $50^{\circ} \mathrm{e}$ atitude média próxima de 110/50 (Fig. 5e). As dobras de charneiras curvas, que podem ser designadas de dobras em bainha, possuem dimensões centimétricas. Elas se desenvolvem, principalmente, nos itabiritos em horizontes discretos formando tapetes de dobras em bainha (Fig. 6). Foram observadas na região de charneira do flanco inverso, nos domínios 1 e 2, cujas atitudes são paralelas às das dobras $\mathrm{F}_{1} \mathrm{O}$ sentido de fluxo indica movimento para sudeste.

A lineação mineral é caracterizada pela orientação preferencial de cristais de hematita, quartzo e moscovita. A orientação é subparalela à lineação de interseção $\mathrm{L}_{1}\left(\mathrm{~S}_{0} \times \mathrm{S}_{1}\right)$ e eixos de dobra da primeira fase ( $\left.B_{1}\right)$. A lineação mineral apresenta caimentos moderados para ESE em torno de 100/55. No extremo sul do domínio I (Fig. 4a) ela apresenta orientações anômalas, sendo encontrada com caimentos subhorizontais ora para NW ora para SE (Fig. 5d).

Estruturas da Fase D, CLIVAGEM, DOBRAS, LINEAÇÕESE FALHAS A clivagem $\mathrm{S}_{2}$ é uma trama planar penetrativa definida pela orientação preferencial de minerais como hematita, quartzo e moscovita, estando desenvolvida em todos os setores da estrutura de Ouro Fino. Sua geometria varia de uma clivagem contínua a uma clivagem espaçada cuja orientação média varia de 044/54 a 074/53 (Fig. 7a). A clivagem $\mathrm{S}_{2}$ ocupa a posição plano-axial de dobras da segunda fase de deformação.

As dobras $\mathrm{F}_{2}$ comumente possuem comprimentos de onda que variam de alguns decímetros a metros. São dobras abertas a apertadas com assimetria indicando vergência para W. As charneiras rumam ora para norte ora para sul com caimentos moderados (Fig. 7b). O sinforme Córrego da Flechas é uma dobra da fase $D_{2}$ cujo traço axial, no segmento sul, acompanha subparalelamente o traço da falha Córrego das Flechas. Admitese que este sinforme tenha continuidade para o segmento setentrional acompanhando o traço dessa falha. Geneticamente, o sinforme Córrego das Flechas é uma dobra de arraste associada à lapa da falha de empurrão Córrego das Flechas que possui movimento dirigido para oeste. A figura 8 é uma ilustração da geometria do sinforme Córrego das Flechas e dobras associadas na porção sul do sinclinal.

A foliação $S$, está dobrada por este segundo evento, foi preferencialmente reorientada de modo a possuir valores modais com mergulhos para NE, Ee ENE (Fig. 5b).

A lineação de interseção $L_{2}$ entre o acamamento $\mathrm{S}_{0}$ e a foliação $\mathrm{S}_{2}$, possui caimentos suaves, principalmente para NW ou para SE e raramente nas posições intermediárias(Fig. 7c).

O segundo evento de deformação gerou as falhas de empurrão 


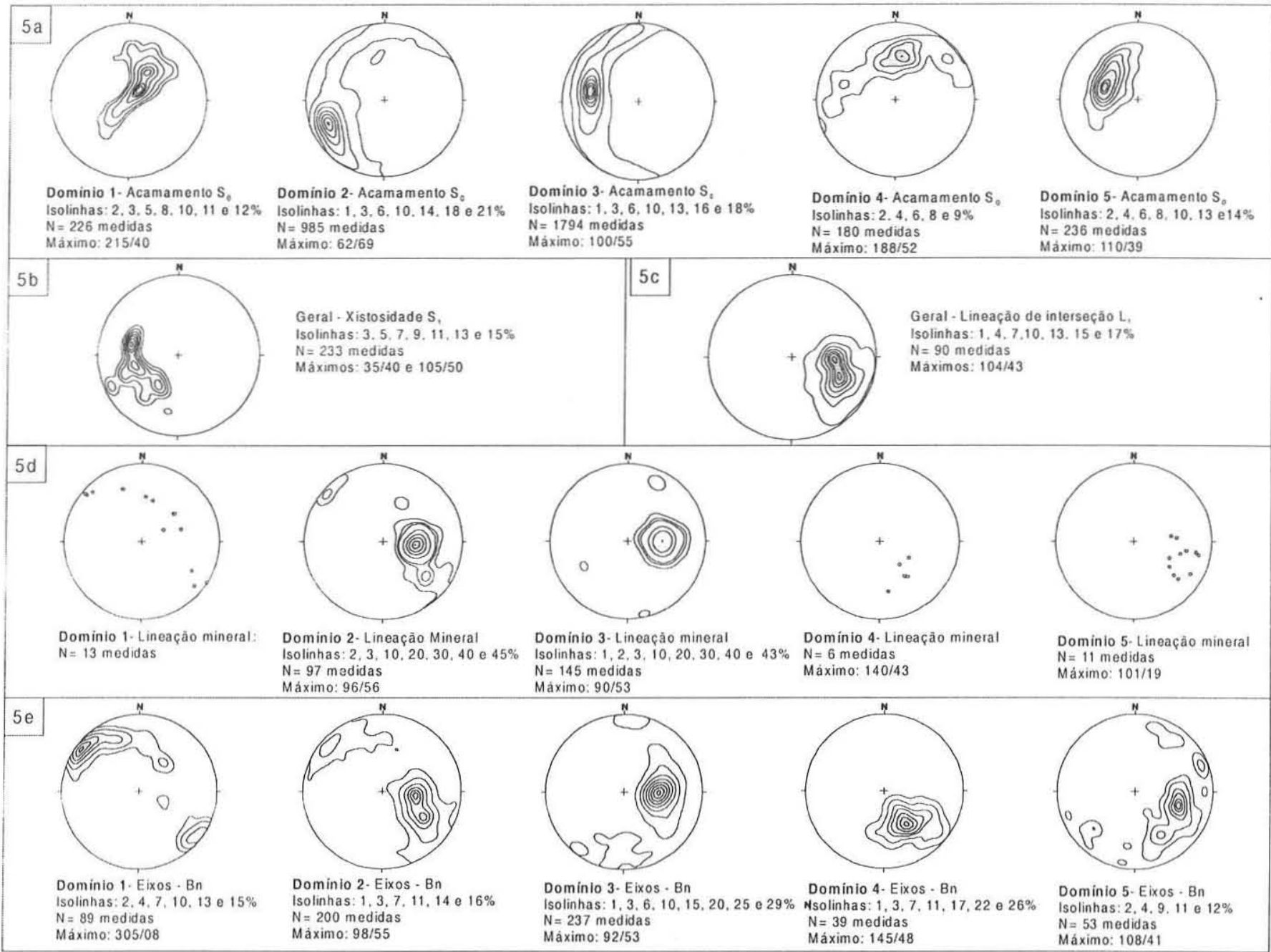

Figura 5 - Diagramas estereográficos para as principais estruturas observadas. (a) acamamento (b) xistosidade $S_{\rceil}$; (c) lineações de interseção; (d) eixos de dobras e (e) lineações de estiramento mineral.

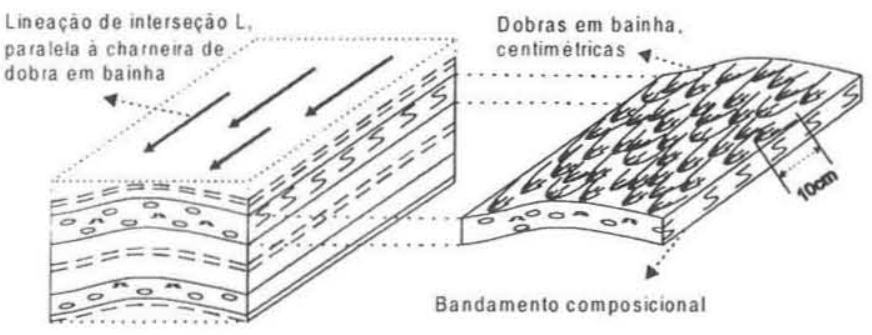

Figura 6-Bloco diagrama esquemático mostrando as dobras em bainha mesoscópicas no plano do bandamento composicional em itabirito. Dobras em bainha somente foram observadas na zona da charneira.

do Fundão, Ouro Fino e Córrego das Flechas. A Falha do Fundão delimita a estrutura de Ouro Fino na região meridional. Ocupa uma posição de rampa oblíqua com direção NW-SE e emerge a oeste do Sinclinal Ouro Fino em posição de rampa frontal indo seccionar o Sinclinal Gandarela, a norte. Na região de inflexão da Falha do Fundão emergem duas falhas subsidiárias que envolvem a estrutura de Ouro Fino, a oeste tem-se a falha de Ouro Fino e a leste a falha Córrego das Flechas (Fig. 3). Próximo à Falha do Fundão o acamamento sofre intensa transposição sendo comum a xistosidade $\mathrm{S}_{2}$ evoluir para a foliação milonítica $\mathrm{Sm}_{2}$. Essa foliação milonítica apresenta direção média NW-SE com mergulhos médios para NE.

Além de ocupar a posição plano-axial de dobras da segunda fase, a clivagem $\mathrm{S}_{2}$ é contemporânea às falhas de empurrão.

Estruturas da Fase $\mathrm{D}_{3}$ CLIVAGEM, DOBRAS ELINEAÇÕES A foliação $\mathrm{S}_{3}$ é representada pela clivagem disjuntiva sendo observada em todos os domínios do Sinclinal Ouro Fino. A direção geral da clivagem $\mathrm{S}_{3}$ éEW, com mergulhos subverticais ora para $\mathrm{N}$ ora para $\mathrm{S}$ (Fig. 7d). As dobras $\mathrm{F}_{3}$ são dobras abertas com charneiras apresentando caimentos para E e geradas durante a terceira fase, relacionada ao encurtamento NS sofrido pelo sinclinal. A lineação de interseção $L_{3}$ entre o acamamento $S_{0}$ e a clivagem espaçada $S_{3}$ apresenta direção EW com caimentos variados ora pra $E$ ora para 


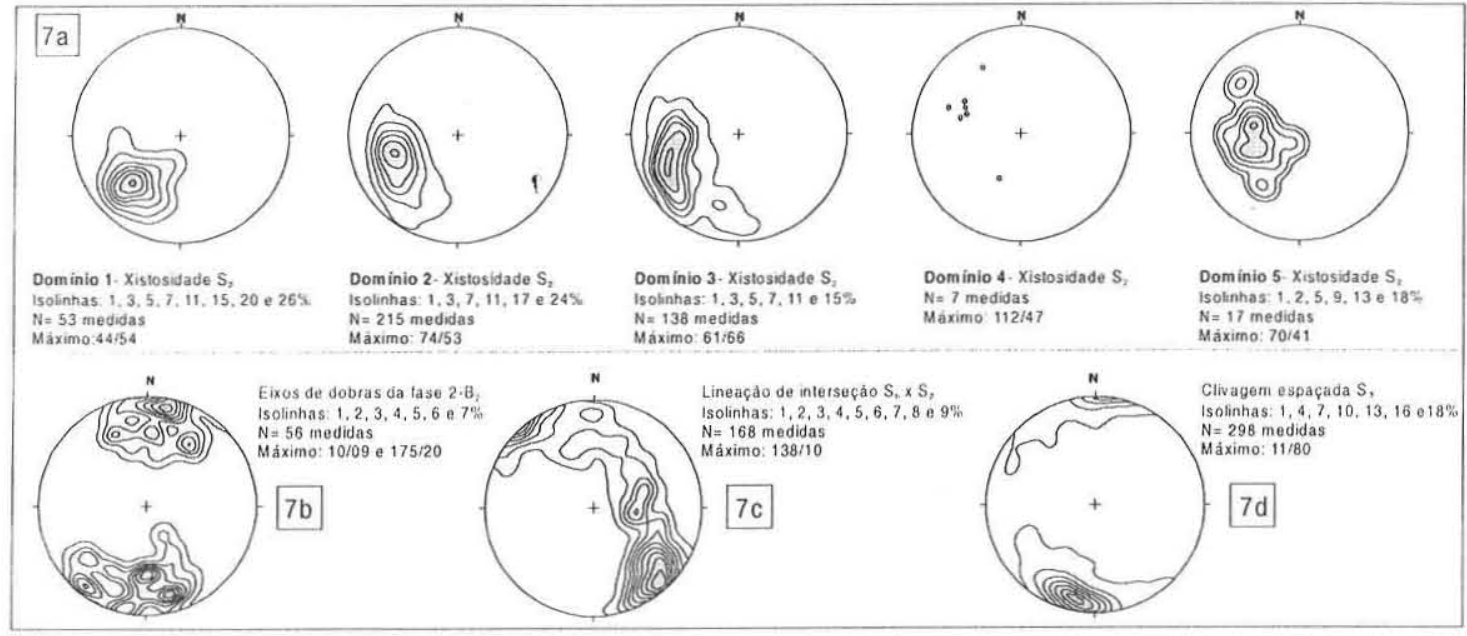

Figura 7 - Diagramas estereográficos para as principais estruturas da segunda e terceira fase de deformação. a) clivagens contínuas e espaçadas $S_{2}$; b) eixos de dobras $B_{2}$; c) lineações de interseção $L_{2}$, d) clivagem espaçada $S_{3}$.

W. A clivagem $\mathrm{S}_{3}$ apresenta relação de corte sobre as foliações $\mathrm{S}_{\text {, }}$ e $S_{2}$ sendo, portanto, mais jovem que elas.

Estruturas da Fase D, CLIVAGEM EDOBRAS A clivagem de crenulação $S_{4}$ possui direção NNE-SSW e mergulhos elevados para WNW. Ocupa posição plano axial de mesodobras e crenulações cujas charneiras apresentam caimentos suaves ora para norte ora para sul. Essa clivagem é comumente encontrada em níveis metapelíticos presentes nos itabiritos da Formação Cauê e principalmente nos filitos da Formação Batatal.

As dobras $\mathrm{F}_{4}$ são caracterizadas por mesodobras e crenulações com eixos na direção $\mathrm{N}-\mathrm{S}$ e caimentos suaves ora para norte, ora para sul. Foram observadas dobras $\mathrm{F}_{4}$ que obliteram ou afetam as estruturas anteriores à esta fase.

\section{DISCUSSÃO E CONSIDERAÇÕES FINAIS Cinemática da} primeira fase de deformação As estruturas da primeira fase de deformação são dominantes no Sinclinal Ouro Fino. A xistosidade $\mathrm{S}_{1}$ é plano-axial de dobras $\mathrm{F}_{1}$ apertadas e reclinadas, com charneiras $\mathrm{B}_{1}$ apresentando caimento moderado para ESE. A lineação de interseção $L_{1}$, as charneiras de dobras $B_{1}$ e a lineação mineral são feições lineares notavelmente paralelas entre si associadas a dobramentos do tipo flexural nesta primeira fase. Essas observações sugerem que a lineação mineral representa uma lineação do tipo "b". As dobras F, estão presentes desde a escala microscópica à mesoscópica nos itabiritos da Formação Cauê, e nas rochas encaixantes das formações Moeda e Batatal. O estilo das dobras mesoscópicas $F_{1}$ em torno da estrutura de Ouro Fino, "S" no flanco oeste ou flanco normal e "Z" no flanco leste ou flanco inverso, define o fechamento estrutural na região meridional da mesma. A orientação do eixo do Sinclinal Ouro Fino é definida pelas dobras de $2^{\mathrm{a}}$ ordem e pela atitude média da lineação de interseção L . Dessa forma, o Sinclinal Ouro Fino é uma dobra reclinada, ao contrário de uma dobra normal inclinada com charneira em posição submeridiana, como anteriormente admitida por Dorr (1969) e Fonseca (1990) (Fig. 9).

Cinemática da segunda fase de deformação A segunda fase deformação é a responsável pela geração de dobras abertas a

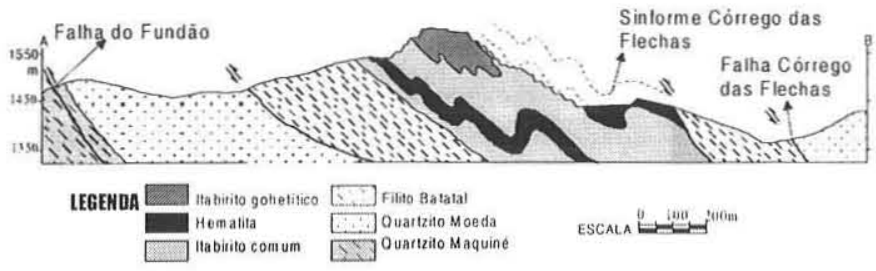

Figura 8-Seção geológica A-B, cortando a porção meridional do sinclinal.

fechadas com eixos subhorizontais orientados em posição submeridiana. A estrutura dominante em escala de mina é o sinforme Córrego das Flechas. É uma dobra de arraste situada na lapa da falha Córrego das Flechas. As dobras dessa fase apresentam clivagens plano-axiais $S_{2}$ com direção preferencial NW-SE e mergulhos moderados para NE (Fig. 7a). O transporte tectônico e a vergência são de leste para oeste. Estas estruturas são redobradas pela fase $\mathrm{D}_{3}$, originando dobras de eixo $\mathrm{E}-\mathrm{W}$ observáveis em escala de mapa (Fig. 3). E por fim uma fase tênue de dobramento com desenvolvimento de crenulações e mesodobras de direção axial $\mathrm{N}-\mathrm{S}$ se superpõem às estruturas anteriores.

Hipótese sobre a evolução tectônica do Sinclinal Ouro Fino Em escala sub-regional, a estrutura de Ouro Fino é caracterizada como uma dobra que tem em seu núcleo, nesta ordem, as unidades intermediárias e basais do Supergrupo Minas de idade Paleoproterozóica (Babinski et al. 1995) e envolvida pela seqüência metapelítica do Supergrupo Rio das Velhas de idade Neo-Arqueana (Carneiro 1992, Machado et al. 1992). Esta relação constitui uma situação tectônica incomum, considerando que o fechamento da dobra se dá no setor meridional da estrutura, sendo corroborado pelas relações de acamamento e xistosidade e pelas dobras subsidiárias em padrão "S" e em " $Z$ ", respectivamente, nos flancos oeste e leste. Essas relações permitem redefinir a estrutura de Ouro Fino como uma dobra sinclinorial reclinada, com eixo apresentando caimento moderado para ESE. A lineação mineral observada no Sinclinal Ouro Fino é interpretada como uma trama tectônica do 
tipo "b". Este paralelismo entre a lineação mineral e a lineação de interseção de atitude E-W tem sido descrito e observado em todo o Quadrilátero Ferrífero (Guild 1957, Gair 1962, Endo 1988, Belo de Oliveira \& Vieira 1987, Endo \& Chemale Jr 1992, Endo 1997, TrzaskosLipski 2001, Almeida et al. 2002). Barbosa (1949), Pericon \& Quèmenèur (1982), Ladeira \& Viveiros interpretam a lineação de interseção) E-W como direção de charneiras de dobras regionais e, neste caso, a lineação mineral representaria uma trama linear do tipo "b". Por outro lado, tem sido interpretado e admitido também como produto de rotação da lineação de interseção em direção ao fluxo cisalhante e, neste caso, a lineação mineral decorrente seria um "L" tectonito. (Endo 1988, Fonseca 1990, Alves 1991, TrzaskosLipski 2001, Rosière et al. 2001).

O modelo tectônico proposto consiste dos seguintes estágios:

(1)- As estruturas de primeira ordem são geradas no primeiro estágio pelo dobramento em estilo isoclinal envolvendo as camadas dos supergrupos Minas e Rio das Velhas, seguido de dobramento coaxial. As hipóteses para a origem desta feição tectônica pode ser entendida como decorrente de dois processos distintos e exclusivos:

Primeira hipótese: OSinclinal Ouro Fino representaria uma dobra recumbente de segunda ordem do flanco normal de um dobramento isoclinal regional com vergência para norte. Associa-se a este dobramento xistosidades plano-axiais e lineações minerais e de interseção paralelas aos eixos de dobras Fl (Fig. 10A).

Segunda hipótese: O Sinclinal Ouro Fino representaria um sinclinal antifórmico resultante do redobramento coaxial do flanco inverso de uma dobra isoclinal de caráter regional. Neste caso, a vergência do dobramento da primeira fase pode ser tanto para norte quanto para sul. (Fig. 10B).

Os elementos estruturais da fase mais antiga relacionada ao dobramento isoclinal, fase pré-Fl, estaria representado por raras

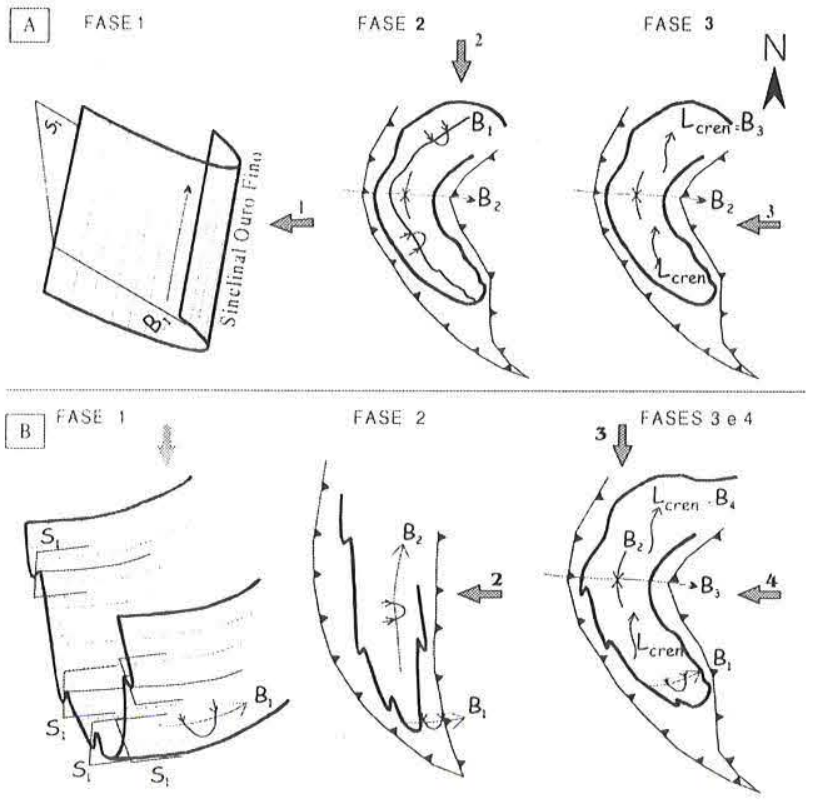

Figura 9 - Figura esquemática comparativa entre o modelo estrutural de Dorr (1969) e Fonseca (1990) (A) com o modelo estrutural proposto (B). As setas numeradas de $I$ a 4 representam os sentidos de transporte tectônico. dobras isoclinais e dobras em bainha com atitudes estruturais similares aos da fase F1. Entretanto, Barbosa (1949), Pericon \& Quèmenèur (1982), Endo (1997) e Almeida et al. (2002) descrevem dobramentos isoclinais (nappe) com vergência para S-SW, em outras regiões do QF, atribuídos ao evento orogênico Minas.

(2)- No segundo estágio o Sinclinal Ouro Fino é seccionado pelo sistema de falhas do Fundão. Uma megadobra sinfórmica de arraste é formada na lapa da falha Córrego das Flechas. O traço axial do sinforme é paralelo ao traço dessa falha. A vergência tectônica deste estágio é de E para W.

(3)- No terceiro estágio, através de uma compressão N-S, tanto o sinclinal Ouro Fino quanto o sinforme Córrego das Flechas são redobrados, resultando em direções axiais E-W. A dobra notável decorrente desta compressão é a feição em bumerangue delineada pela trajetória das camadas do Supergrupo Minas, cujo eixo possui caimento moderado para $\mathrm{E}$.

(4)- O último estágio corresponde à geração de estruturas N-S, notadamente crenulações e mesodobras com eixo N-S. A clivagem de crenulação associada apresenta mergulhos elevados para oeste.

Agradecimentos À Companhia Minas da Serra Geral pelo apoio logístico, e acesso ao banco de dados da Mina de Capanema. A.S.P.F. agradece à FAPEMIG/FIEMG pela concessão de bolsa de mestrado. Aos revisores da RBG pelas sugestões ao manuscrito.

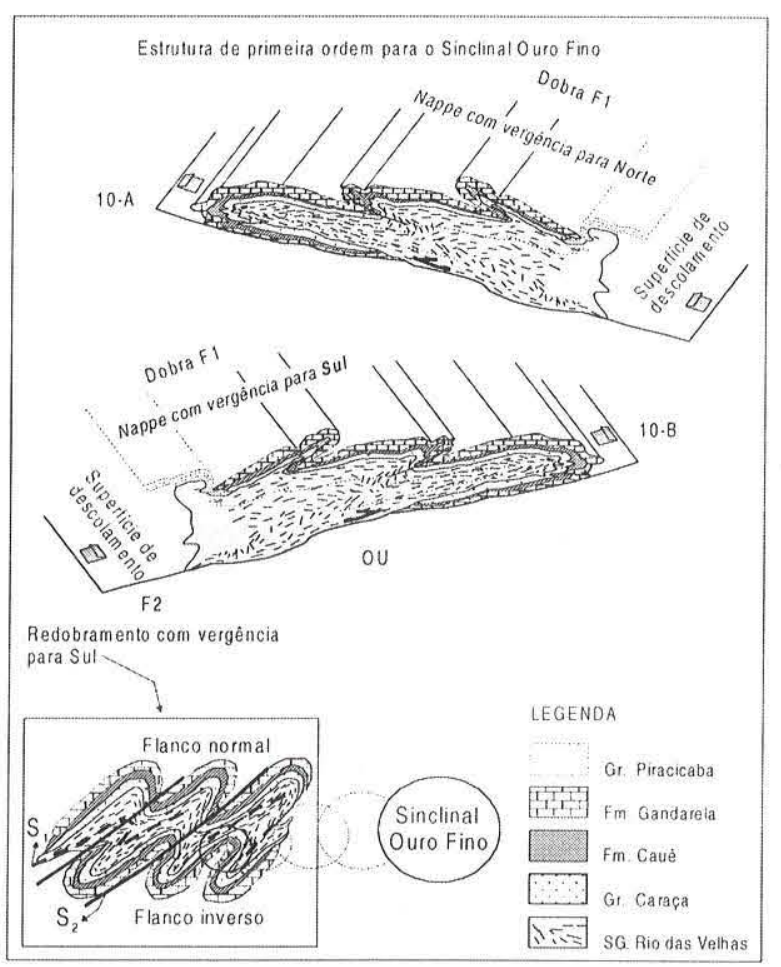

Figura 10-Modelo esquemático para a evolução estrutural do Sinclinal Ouro Fino. A)- Sistema de nappe com vergência para norte mostrando o Sinclinal Ouro Fino como uma dobra de $2^{a}$ ordem. Esta hipótese é similar ao apresentado por Ladeira \& Viveiros (1984); B)-Sistema de nappe com vergência para sul. O Sinclinal Ouro Fino representa uma dobra de $2^{a}$ ordem resultante do redobramento do flanco inverso dessa nappe. 


\section{Referências}

Almeida L. G., Endo I.. Fonseca M. A. 2002. Sistema de nappes na porção meridional do Quadrilátero Ferrífero, MG. In: SBG, Congr. Bras. Geol., 41, João Pessoa, Paraíba, Resumos, 615 p.

Alves J. A. C. 1991. Reconstrução estocástica de um modelo geológico: mina de São Luis - Quadrilátero Ferrífero, $M G$. Departamento de Geologia, Escola de Minas da Universidade Federal de Ouro Preto, Ouro Preto, Dissertação de Mestrado, 215 p.

Babinski M., Chemale Jr. F., Schumus W. R. 1995. The Pb/Pb age of the Minas Supergroup carbonate rocks, Quadrilátero Ferrífero, Brazil. Prece. Res. 72:235-245

Barbosa O. 1949. Contribuição à geologia do centro de Minas Gerais. Min. e Metal., 14(79):3-19

Belo de Oliveira O. A. \& Vieira M. B. H. 1987. Aspectos da Deformação Dúctil e Progressiva no Quadrilátero Ferrífero. In: SBG/Núcleo Minas Gerais, Simpósio de Geologia de Minas Gerais, 4. Belo Horizonte, 1987. Anais, 237-253

Carneiro M. A. 1992. O Complexo Metamórfico Bonfim Setentrional Quadrilätero Fierriffero. Minas Gerais: Litoestratigrafia e evolução geológica de um segmento de crosta continental do Arqueano. Instituto de Geociências, Universidade de São Paulo, São Paulo, Tese de Doutoramento, $233 \mathrm{p}$.

Dorr J. V. N. II. 1969. Physiographic, Stratigraphic and Structural development of the Quadrilatero Ferrifero, Minas Gerais, Brazil. Washington, USGS/DNPM, Prof. Paper 641-A, $110 \mathrm{p}$.

Endo I. 1988. Análise estrutural qualitativa no minério de ferro e encaixantes na Mina de Timbopeba - Borda leste do Quadrilátero Ferrífero. Mariana, MGi. Departamento de Geologia, Universidade Federal de Ouro Preto, Dissertação de Mestrado, 112 p.

Endo I. 1997. Regimes tectônicos do Arqueano e Proterozóico no interior da Placa Sanfranciscana: Quadrilátero Ferrifero éreas adjacentes, Minas Gerais. Instituto de Geociências, Universidade de São Paulo, Tese de Doutoramento, 243 p.

Endo I. \& Chemale Jr F. 1992. Modelo de evolução cinemática do Sinclinal Alegria e adjacências, Quadrilátero Ferrífero - MG. Rev. Esc. Minas, 45(1/2):24-27

Fonseca M. A. 1990. O Sinclinal de Ouro Fino: Análise descritiva e cinemática de um segmento do Sistema Fundão, Quadrilátero Ferrífero, Minas Gerais. Departamento de Geologia, Universidade Federal de Ouro Preto, Ouro Preto, Dissertação de Mestrado, 120 p.

Fonseca M. A. \& Alkmim F. F. 1992. O Sinclinal de Ouro Fino e sua relação genética ao sistema Fundão, Quadrilátero Ferrífero, MG. Rev. Esc. Minas, 45(1/2):65-67

Franco A. S. P. 2003. Geometria e evolução tectônica do Sinclinal Ouro Fïno e implicações para a mineralização ferrífera, Quadrilátero Ferriffero, MG. Departamento de Geologia, Universidade Federal de Ouro Preto, Ouro Preto, Dissertação de Mestrado, 99 p.

Gair J. E. 1962. Geology and ore deposits of Nova Lima and Rio de Pedras quadrangles, Minas Gerais, Brazil. Washington, USGS/ DNPM, Prof. Paper 341-A, 67 p.

Guild P. W. 1957. Geology and mineral resources of the Congonhas district, Minas Gerais, Brazil. Washington, USGS/DNPM, Prof. Paper 290, 89 p.

Harder E. C. \& Chamberlin R. T. 1915. The geology of central Minas Gerais, Brazil. Jour: Geol., 23:341-378

Ladeira E. A. 1980. Metallogenesis of gold at the Morro Velho mine and in the Nova Lima district, Quadrilátero Ferrifero, Minas Gerais. University of Western Ontario, Canadá, PhD. Thesis, 272 p.

Ladeira E. A. \& Viveiros J. F. M. 1984. Hipótese sobre a estruturação do Quadrilátero Ferrífero com base nos dados disponiveis. SBG/
Núcleo Minas Gerais, Belo Horizonte, Boletim 4, 18 pp.

Machado L. Fo., Ribeiro M. W., Gonzalez S. R., Schenini C. A., Santos A. N., Palmeira R. C. B., Teixeira W., Castro H. E. F. 1983. Geologia das Folhas 23/24 Rio de Janeiro e Vitória. Rio de Janeiro, DNPM/ MME/SG. Projeto RadamBrasil. Levantamento de Recursos Naturais, 32.304 p.

Machado N., Noce C. M., Ladeira E. A., Belo de Oliveira O. A. 1992. U$\mathrm{Pb}$ geochronology of Archean magmatism and Proterozoic metamorphism in the Quadrilátero Ferrífero, southern São Francisco Craton, Brazil. Geol. Soc. Am. Bull., 104:1221-1227

Maxwell C. H. 1960. Mapa Geológico da Quadrícula de Capanema, Minas Gerais. Washington, USGS/DNPM, Prof. Paper 341J, 72 p.

Maxwell C. H. 1972. Geology and ore deposits $f$ the Alegria district, Brazil. Washington, USGS/DNPM, Prof. Paper 341J, 72 p.

Menezes M. G. 1988. Geologia e ocorrência aurífera da faixa Maquiné ao sul da quadrícula de Capanema, Quadrilátero Ferrífero, Minas Gerais. Universidade Federal de Brasília, Brasília, Dissertação de Mestrado, $80 \mathrm{p}$

Moraes Rego L. F. de 1933. As jazidas de Ferro do Centro de Minas Gerais. Belo Horizonte, Imprensa Oficial, 81 p.

O'Rourke J. E. 1957. The Stratigraphy of the metamorphic rocks of the Rio de Pedras and Gandarela Quadrangles, Minas Gerais, Brazil. University of Wisconsin, Wisconsin, Ph.D. Thesis, $106 \mathrm{p}$.

Pericon H.Z. \& Quèmenèur J.J.G. 1982. Tectônica de nappes e séries transgressivas no Quadrilátero Ferrífero. In: SBG, Congr. Bras. Geol., 32. Salvador, Anais, 1:153-167

Rodrigues L. C. R., Chemale Jr F., Jost H. 1993. O posicionamento estratigráfico dos quartzitos da Serra do Caraça. In: SBG/Núcleo Minas Gerais, Simpósio de Geologia de Minas Gerais, 7, Belo Horizonte, 1993. Anais, 34-38. (Boletin 12)

Rosière C. A., Siemes H., Quade H., Brokmeier H-G, Jansen E. M. 2001. Microstructures, textures and deformation mechanisms in hematite. Jour:of Struct. Geol., 23(9): 1429-1440

Sad J. H. G. \& Castro F. D. C. de 2000. Geologia econômica dos módulos Il e III, Serra do Ouro Fino, Santa Bárbara, MG. Belo Horizonte, Cia. Geosol, 92 p. (Relatório Interno)

Schobbenhaus C., Campos D. A., Derze G. R., Asmus H. E. 1984. Mapa Geológico do Brasil e da Área Oceânica Adjacente. Ministério das Minas e Energia-DNPM, Brasília, Brasil, (1:2.500.000)

Schorscher H. D. 1978. Komatiitos na estrutura greenstone belt da Série Rio das Velhas, Quadrilátero Ferrífero, Minas Gerais, Brasil. In: SBG, Congr. Bras. de Geol., 30, Recife, Resumos, 1:292-293

Soares A. C. P., Dardenne M. A., Hasui Y., Castro F. D. C., Carvalho M. V. A., Reis A. C. 1994. Mapa geológico do Estado de Minas Gerais. COMIG. Belo Horizonte. (1:1.000.000)

Trzaskos-Lipski B. 2001. Os atributos estruturais do minério de ferro granulado da mina de Casa de Pedra, Congonhas - MG, e sua resposta no processo de redução em alto forno. Departamento de Geologia, Escola de Minas da Universidade Federal de Ouro Preto, Ouro Preto, Dissertação de Mestrado, 136 p.

Vaz de Melo M. T. \& Seabra Jr. A. A. G. 2000. Geologia econômica do jazimento de minério de ferro da Mina de São Vicente, Itabiritomina de Capanema, MG. Belo Horizonte, MTV, 69 p. (Relatório Interno)

Manuscrito A-1367

Recebido em 29 de agosto de 2002

Revisão dos autores em 22 de fevereiro de 2004 Revisão aceita em 15 de março de 2004 